\title{
Os mercados financeiros internacionais e a volatilidade cambial no Brasil
}

\section{Luciano Ferreira Gabriel José Luis Oreiro}

Nas últimas décadas, a remoção dos controles sobre o movimento internacional de capitais e a desregulamentação dos mercados financeiros domésticos, combinadas com o rápido progresso tecnológico em computação e comunicações, bem como a diversificação e sofisticação crescentes dos instrumentos financeiros, produziram uma ampliação extraordinária dos mercados, especialmente dos fluxos internacionais de capitais.

O aumento destes fluxos internacionais de capitais e a tendência à integração dos mercados criaram novos elementos na condução das políticas econômicas nacionais. A expansão das operações financeiras internacionais coloca limites à condução destas políticas, em especial no campo monetário-financeiro. ${ }^{1}$

Segundo Kregel (2004) é praticamente indiscutível que, a partir da década passada, os mercados financeiros tenham se tornado mais integrados no âmbito global do que o mercado de bens, chegando também a dominar as decisões de produção real e os fluxos comerciais. A despeito dessas mudanças, a atenção dos economistas e analistas de políticas continua voltada para os efeitos do comércio de mercadorias e serviços sobre o setor real.

A maior integração e desregulamentação dos mercados financeiros internacionais aumentaram o grau de interdependência e também o risco de incompatibilidade entre as políticas monetárias e financeiras adotadas por diferentes países. Isso ocasionou uma crescente instabilidade financeira, mais evidente nos últimos tempos em forma de crises cambiais, que afetou sobremaneira a condução das políticas nacionais.

No que se refere, em especial, às políticas monetárias e financeiras, essas mudanças no quadro financeiro internacional têm mostrado cada vez mais que há uma dificuldade crescente por parte dos bancos centrais de sustentarem determinados tipos de regimes cambiais, principalmente aqueles regimes que se caracterizam por ancoragem cambial, isto é, aqueles que estabelecem sistemas ajustáveis de câmbio fixo, prefixações, bandas cambiais, dentre outros. $^{2}$

\footnotetext{
${ }^{*}$ Mestre em Desenvolvimento Econômico pela UFPR. Endereço eletrônico: lucianofg@gmail.com

** Doutor em Economia pelo IE/UFRJ, Professor do Departamento de Economia da UFPR e Pesquisador do CNPq. Endereço eletrônico: joreiro@ufpr.br. Síte pessoal: http://www.joseluisoreiro.ecn.br

${ }^{1}$ Para uma melhor discussão deste aspecto veja Batista Jr. (1998) e Oreiro (2004).

2 Para uma análise das características dos diferentes regimes cambiais veja Garofalo Filho (2000)
} 
Tomando-se por base o modelo Mundell-Fleming e a análise desenvolvida por Frankel, Schumukler e Servèn (2000), diante da volatilidade dos fluxos de capitais e à ameaça de ataques especulativos, os regimes cambiais extremos, ou seja, o regime de câmbio livremente flutuante e o regime de câmbio fixo não ajustável seriam, pelo menos numa primeira análise, imunes a estes ataques ${ }^{3}$. No que tange a um regime de câmbio fixo não ajustável, a razão disso se encontra na credibilidade que o mesmo obtém dos agentes econômicos em função da irrevogabilidade do mesmo. Já em um regime de câmbio livremente flutuante, a livre flutuação da taxa de câmbio teria o efeito de tornar o regime altamente resistente a um ataque ou a uma grande volatilidade dos fluxos de capitais sem o colapso do regime cambial.

Essa visão otimista sobre a performance dos regimes cambiais extremos deve, no entanto, ser vista com mais cautela. Com efeito, Obstfeld e Rogoff (1995) destacam que os regimes de câmbio fixo não duram, em geral, mais do que cinco anos. Na última década, tivemos várias crises cambiais e financeiras nas economias em desenvolvimento que adotaram regimes de câmbio fixo ou semi-fixo. Podemos listar as crises do México (1994), Ásia (1997), Rússia (1998), Brasil (1999), Turquia e Argentina (2001). Este último caso é emblemático por ter adotado um regime de câmbio fixo não ajustável.

Os defensores do regime de câmbio livremente flutuante argumentam que o mesmo estaria imune a esse tipo de crise cambial uma vez que a ocorrência de choques adversos sobre a economia imporia um ajuste automático da taxa nominal de câmbio, mantendo-se assim o equilíbrio interno e externo. No entanto, os países emergentes possuem uma série de peculiaridades que os distingue das economias desenvolvidas, as quais podem contribuir para tornar pouco eficaz o ajuste da taxa nominal de câmbio. Concretamente devemos destacar que os países emergentes têm, via de regra, as seguintes características: i) moedas não conversíveis internacionalmente (como o dólar ou o euro); ii) grande volatilidade nos fluxos de capitais externos e iii) recorrência e persistência de déficits em transações correntes.

A operação de um regime de câmbio flutuante sob as circunstâncias destacadas acima faz com que a taxa de câmbio nominal seja extremamente volátil, o que, segundo Grenville (2000), gera os seguintes efeitos:

\footnotetext{
${ }^{3}$ De acordo com o modelo Mundell-Fleming, sob hipótese de livre mobilidade de capitais, a política monetária pode ser usada para a expansão dos níveis de emprego e renda, ainda que sujeita às dificuldades impostas pela volatilidade dos fluxos de capitais.
} 
a) inibe os investimentos em capital fixo ao aumentar o risco cambial das operações de importação de bens de capital;

b) obriga o Banco Central a operar com taxas de juros nominais e reais elevadas para impedir o repasse da depreciação do câmbio para os preços ${ }^{4}$. As elevadas taxas de juros desestimulam o crescimento econômico ao impedir que a demanda agregada acompanhe a expansão da capacidade produtiva, o que resulta em grande capacidade ociosa e termina por afetar de forma desfavorável o investimento em ampliação da capacidade produtiva, reduzindo assim o crescimento potencial da economia.

O caso brasileiro no período 2001/2002 é bastante ilustrativo a respeito das dificuldades operacionais de um regime de câmbio flutuante num contexto de grande abertura da conta de capitais do balanço de pagamentos. Após a crise cambial de janeiro de 1999, houve uma mudança na situação do balanço de pagamentos brasileiro em função da adoção de um novo modelo de política econômica baseado na adoção regime de câmbio flexível, no aumento do grau de abertura financeira ${ }^{5}$ e na adoção do regime de metas de inflação. No entanto, a adoção do regime de câmbio flutuante, em um ambiente de livre mobilidade de capitais, não conseguiu diminuir de forma sensível a situação de fragilidade externa da economia brasileira. Essa fragilidade em conjunto com o medo de quebra de contratos associado a vitória de um candidato de esquerda (Lula) nas eleições presidenciais de 2002 produziram um sudden stop (parada súbita) do fluxo de capitais para a economia brasileira da ordem de $6 \%$ do PIB, o que resultou numa depreciação do câmbio de $52,50 \%{ }^{6}$ e um aumento dos custos de financiamento externo do Brasil, bem como em dificuldades na rolagem da dívida externa (na forma de empréstimos diretos e títulos). ${ }^{7}$

\footnotetext{
${ }^{4}$ Esse fenômeno é chamado de pass-through inflacionário.

${ }^{5}$ Como foge do escopo do presente trabalho uma análise sobre a abertura financeira na década de 90 e as medidas liberalizantes aplicadas em 2000, sugerimos a leitura do trabalho de Freitas e Prates (2001) para cobrir esta lacuna.

${ }^{6}$ A desvalorização nominal do Real, em 2002, foi da ordem de 52,5\%, mas chegou a alcançar 62,21\% entre março e outubro. A estrutura peculiar da formação dos preços no Brasil faz com que desvalorizações da taxa de câmbio ou choques exógenos de oferta pressionem a maioria dos preços dos bens e serviços. Como a participação agregada dos bens tradeables e dos que têm preços administrados representa a maior parte do IPCA (Índice de Preços ao Consumidor Amplo), adotado como referência para as metas de inflação, observa-se que a política monetária seja muito mais sensível aos choques exógenos e à variação cambial.

${ }^{7}$ No período de 2001 e 2002 ocorreu uma constelação de eventos os quais contribuíram para o aumento da aversão ao risco dos agentes econômicos internacionais. Poderíamos citar a crise cambial da Turquia em fevereiro 2001, a decretação de moratória da Argentina em dezembro de 2001 e as fraudes contábeis de grandes empresas norte-americanas (para uma maior discussão destes fatos veja Cintra e Farhi, 2003).
} 
Gráfico 1 . Evolução do IGP-DI, IPA-DI e IPCA (1996-2005)

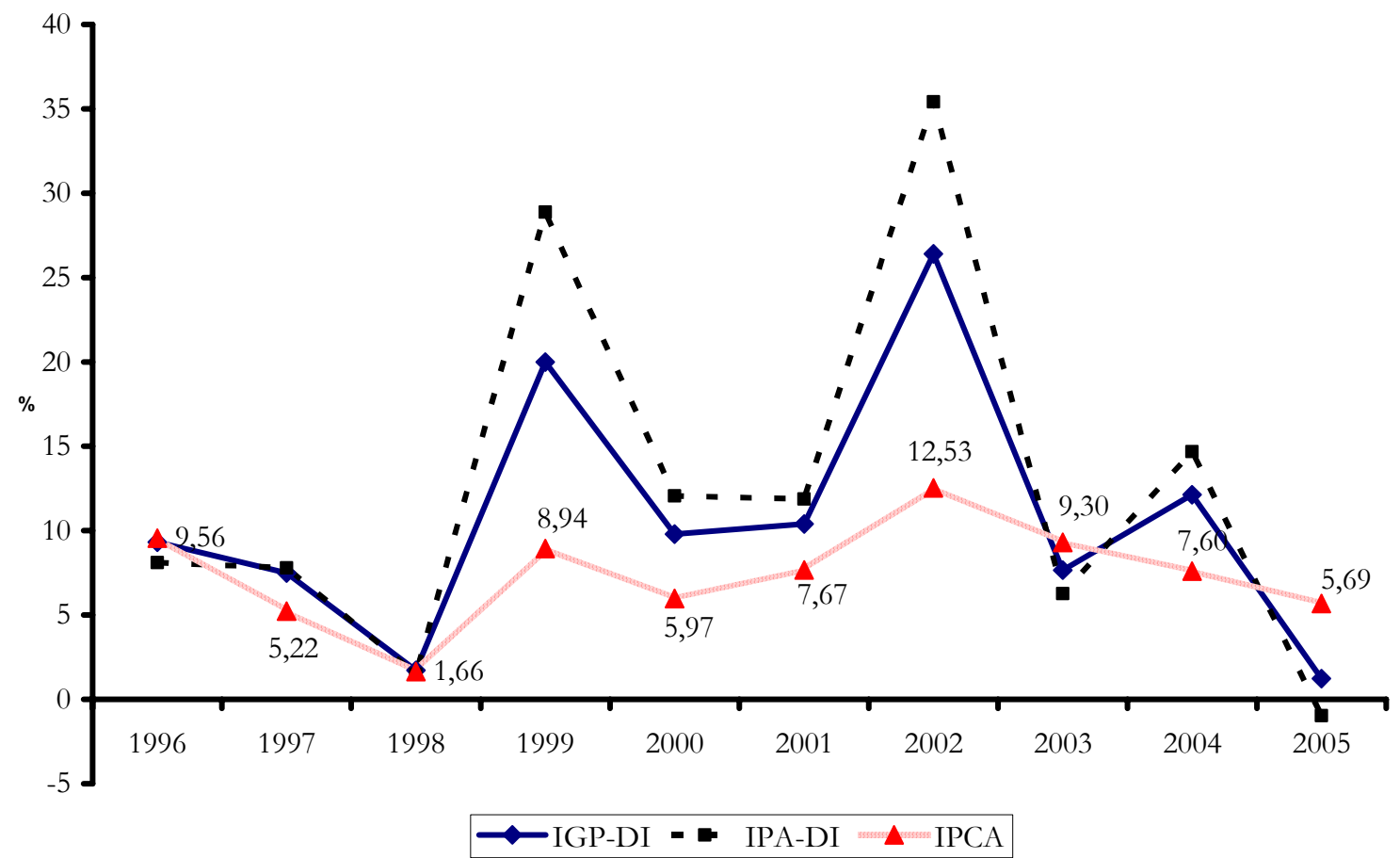

Fonte: IPEA

O efeito do sudden stop dos fluxos de capitais externos gerou custos reais para o Brasil. A forte depreciação da taxa de câmbio acabou por gerar pressões inflacionárias (efeito pass through). ${ }^{8}$ Como nos ataques especulativos na década de 90 , a taxa de juros também foi elevada para conter esta pressão, diminuindo o nível de atividade econômica? .

As repercussões dessa pressão sobre a taxa de câmbio nos períodos de 2001 e 2002 manifestaram-se sobre o nível de preços domésticos, fazendo com que a inflação de 2001 e 2002 superasse a meta de 4\% e 3,5\%, respectivamente ${ }^{10}$ (veja Gráfico 1), fixada pelo governo e incluída em um acordo com FMI. Na tentativa de conter a alta dos preços nos dois períodos, a autoridade monetária se valeu da elevação da taxa de juros. Essas elevações da taxa de juros, no entanto, não tiveram o efeito esperado de reduzir e/ou reverter o ritmo de desvalorização do câmbio uma vez que o efeito da elevação da taxa de juros sobre o estoque da dívida pública atuou no sentido de deteriorar a percepção dos agentes econômicos sobre os fundamentos da economia, levando assim a uma nova rodada de desvalorizações da taxa de câmbio.

\footnotetext{
8 Segundo Barbosa (2004) o efeito deste sudden stop do fluxo de capitais impactou o bem-estar da população através da diminuição significativa do salário real e, conseqüentemente, do consumo real. Tomando o $1^{\circ}$ trimestre de 2002 como base, Barbosa (2004) calcula que a queda do consumo dessazonalizado das famílias até o $4^{\mathrm{o}}$ trimestre medido como percentual do PIB, foi de 3,65\%.

${ }^{9}$ A taxa de crescimento da economia brasileira foi de 1,31\% a.a. em 2001 e de 1,93\% em 2002.
} 
Além da taxa de juros, o Banco Central utilizou-se de outros instrumentos de política monetária e de regulamentação, tais como a redução do nível de alavancagem nas posições de câmbio e a elevação dos depósitos compulsórios dos bancos. Além disso, indicava ao mercado que considerava a desvalorização cambial excessiva ao ofertar volumes elevados de títulos públicos indexados à taxa de câmbio.

Apesar do efeito negativo sobre a taxa de inflação, no que diz respeito às contas externas, a acentuada desvalorização do Real resultou em uma melhora sensível das mesmas, a qual não tinha sido alcançada nos anos de 1999 e 2000. O superávit da balança comercial fechou os anos de 2001 e 2002 em US \$ 2,7 bilhões e US\$ 13,1 bilhões, respectivamente, a balança de serviços e rendas apresentou ligeira redução em 2002.

Os movimentos especulativos contra o Real em 2001 e 2002 se reverteriam somente após a eleição presidencial, a qual era vista pelo mercado como mais um fator amplificador de incertezas no que se referia ao modelo de política econômica a ser adotado após o pleito. Nos últimos meses, verificou-se um movimento de desvalorização da moeda brasileira devido à intensificação das incertezas relativas à evolução futura dos juros nos Estados Unidos, após a última reunião do Federal Reserve (FED), em 10 de maio de 2006, associada ao comportamento desfavorável da inflação e em resposta à elevação no preço do petróleo.

\section{Gráfico 2. Investidores estrangeiros na Bovespa}

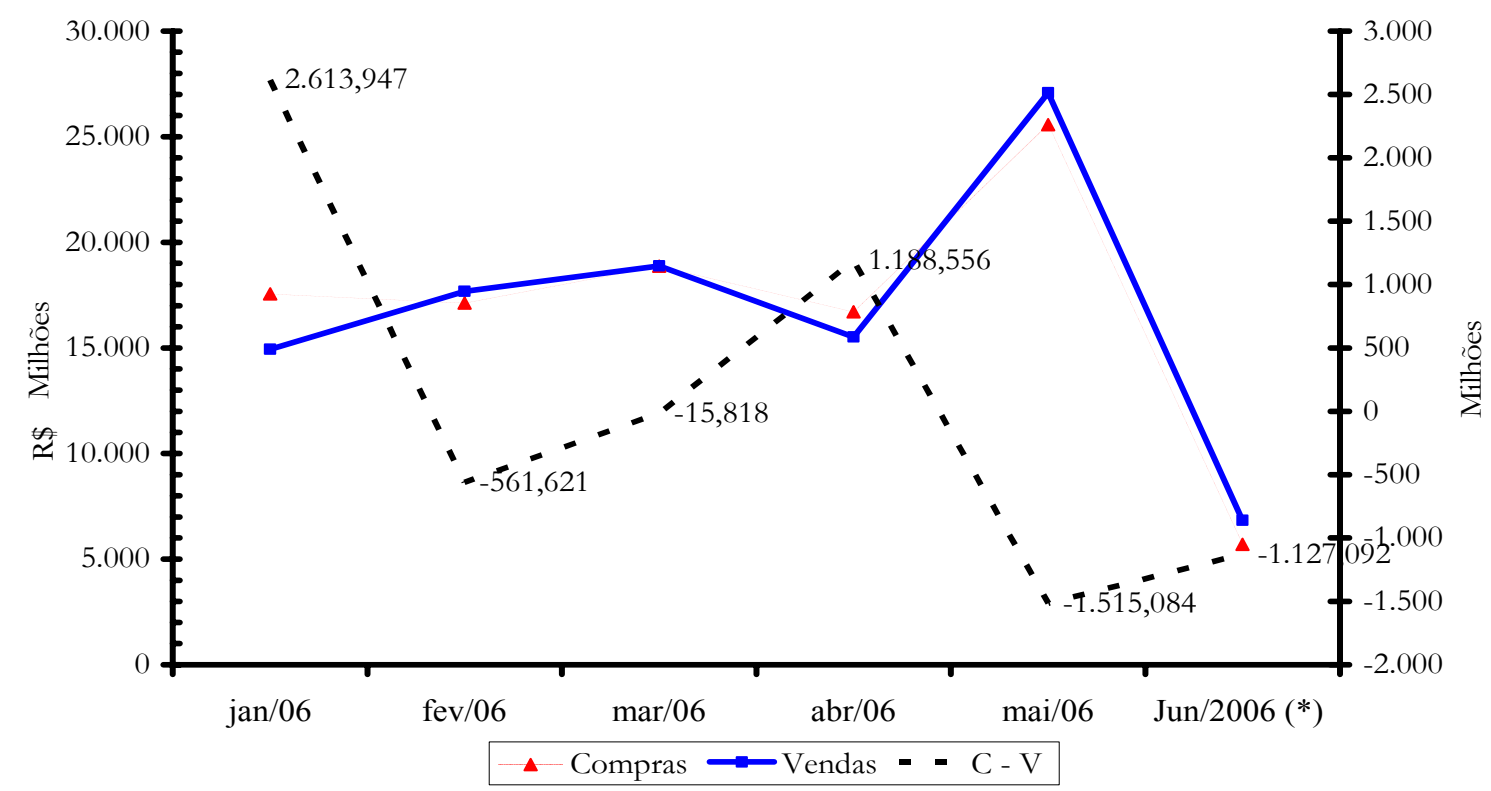

Fonte: Bolsa de Valores de São Paulo (Bovespa).

Nota: * Até o dia 09/06.

${ }^{10}$ Medido pelo IPCA, com limite de tolerância de $2 \%$ para cima ou para baixo. 
Estes fatos mais recentes acabaram por provocar a deterioração dos ativos nos mercados internacionais e volatilidade nos mercados financeiros. No caso do Brasil, a bolsa de valores (Bovespa) chegou a registrar queda de 9,5\% e com saída de recursos estrangeiros da ordem de R\$1,515 bilhões no mês de maio (veja Gráfico 2).

Com o gráfico 3 podemos perceber a volatilidade atípica da taxa de câmbio no mês de maio, em particular, no período de 08/05/06 a 08/06/06, na qual a moeda brasileira registrou uma desvalorização de cerca de 10\% em relação ao dólar.

O elevado volume de divisas que ingressou no país, especialmente até o início de abril de 2006, contribuiu sobremaneira para a valorização do real verificada até recentemente. No entanto, diante do quadro adverso apresentado pelo mercado financeiro internacional, o índice EMBI+ (Emerging Market Bond Index) que no início de 2006 estava em torno de 294 pontos, caiu para aproximadamente 216 pontos no início de maio. Contudo, a partir da segunda semana de maio devido à volatilidade nos mercados financeiros mundiais e ao temor de que a inflação nas economias centrais, como nos Estados Unidos, estaria mostrando uma força acima da esperada até aquele momento, fizeram com que ocorresse um aumento deste indicador da ordem de 54 pontos.

\section{Gráfico 3. Taxa de Câmbio Nominal (compra)}

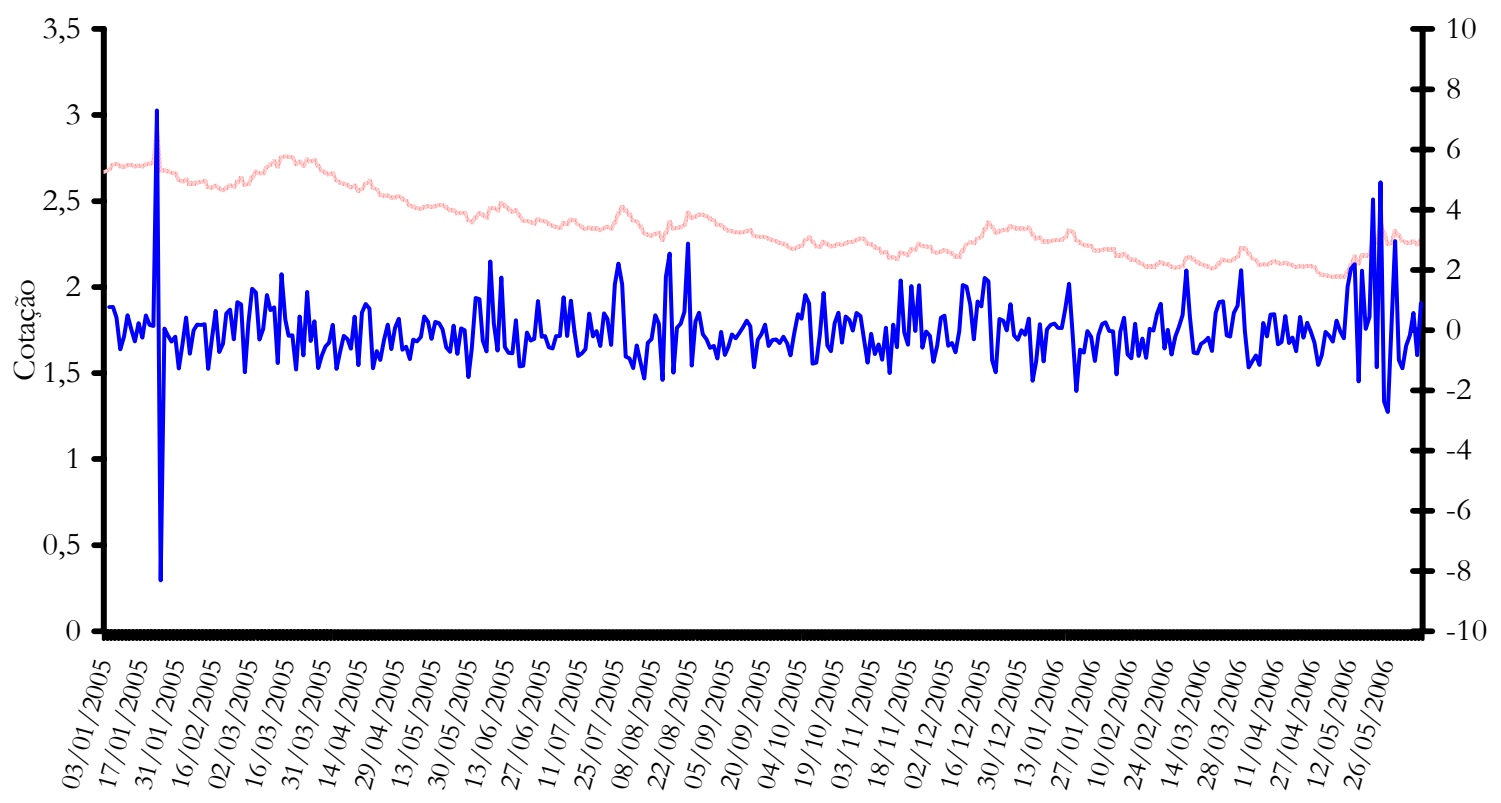

Taxa de Câmbio — Variação Percentual da Taxa de Câmbio

Fonte: Banco Central.

Nota: Valores Diários - 03/01/05 a 08/06/06 
O mesmo movimento de desvalorização e elevação do risco país se verificou em outras economias emergentes. Este fato representa um aumento à aversão dos investidores internacionais ao risco, os quais vêm reduzindo seu grau de exposição em economias emergentes.

Apesar da alta volatilidade cambial verificado no mês de maio, percebe-se que diferentemente dos episódios de 1999 e 2002, as contas externas brasileira estão mais sólidas (ver seção Indicadores Econômicos - Setor Externo) e a perspectiva de crescimento para o ano corrente supera a taxa de $3,5 \%$.

Podemos notar com a análise que desenvolvemos que um dos grandes problemas do câmbio flutuante com elevada mobilidade de capitais está relacionado aos ajustes excessivos (overshooting) em um curto espaço de tempo, o que acaba afetando a economia real (como no período de 2001-2002). Esse fenômeno ocorre devido à rapidez com que os mercados financeiros reagem às expectativas, ao contrário dos setores reais. Nesse sentido, as depreciações da taxa de câmbio não são explicadas estritamente em termos dos fundamentos de uma determinada economia, e a volatilidade sofrida em alguns casos de regimes de câmbio flutuante não são, de igual maneira, explicados por mudanças bruscas nos fundamentos de forma que justifique tal volatilidade.

\section{Referências Bibliográficas}

BANCO CENTRAL. Boletim do Banco Central do Brasil. Brasília-DF: vários números. Disponível em: http://www.bcb.gov.br. Acessado em: jun.2006.

. Economia e Finanças/Séries Temporais. Brasília-DF: Banco Central do Brasil.

Disponível em: <http://www.bcb.gov.br>. Acessado em: jun. 2006.

BARBOSA, C. P. M. Parada Brusca de Financiamento Externo: Fatores Políticos, efeitos Reais. Dissertação de Mestrado em Economia. Rio de Janeiro: PUC-Rio. 2004.

BATISTA JR., P. N. “'Globalização' Financeira e Regimes Cambiais”. Revista de Economia Política., Vol.18, n.2 (70), abr./jun. 1998.

BOVESPA. Balanço Mensal de Maio. São Paulo-SP: BOVESPA. Disponível em: $<$ http//www.bovespa.com.br>. Acessado em: jun. 2006.

CINTRA, M.A.M. e FARHI, M. "O crash de 2002: da 'exuberância irracional' à ganância infecciosa”. Revista de Economia Política, Vol.23, n¹(89), jan./mar. 2003.

FRANKEL, J., SCHMUKLER, S. \& SERVÉN, L. Verifiability and the vanishing Intermediate Exchange Rate Regime, NBER Working Paper 7901. 2000.

FREITAS, M.C. e PRATES, D. A abertura financeira no governo FHC: impactos e conseqüências. Economia e Sociedade, n. 17, p.81-111, 2001.

GAROFALO FILHO, E. Câmbios no Brasil: as peripécias da moeda nacional e a política cambial, 500 anos depois 1.ed. São Paulo: Bolsa de Mercadorias e Futuros (BM\&F). 2000. p.253. 
GRENVILLE, S. Exchange Rate Regimes for Emerging Markets. Sydney: Reserve Bank of Australia Bulletin, November, 2000.

IPEA. Séries do IPEADATA. Disponível em: <http://www.ipea.gov.br>. Acessado em: jun. 2006.

KREGEL, J. Was there an alternative to the Brazilian Crisis? Brazilian Journal of Polical Economy, 3(75):23-28, jul. 1999.

OBSTFELD, M. e ROGOFF, K. Foundations of International Macroeconomics. The MIT Press, Massachusetts Institute of Technology, Cambridge. 1996.

OREIRO, J. L. Autonomia de Política Econômica, Fragilidade Financeira Externa e Equilíbrio do Balanço de Pagamentos. Economia e Sociedade, 13(2): 1-22. 2004. 